\title{
The Future of Free and Open Source Software (FOSS) for Hydrology and Water Resources Management
}

\author{
Amos Kabo-bah*, Xie Yuebo and Justice Odoi
}

State Key Laboratories, Department of Hydrology and Water Resources, Hohai University, Nanjing, China

\begin{abstract}
Free and Open Source Software (FOSS) is rapidly growing in recent times and has changed the way in which licensing costs, sharing and distributions of software programs are managed globally. To a large extent, FOSS offers the cheapest and most effective solutions for technology transfer in software programs towards researchers and students worldwide. FOSS offers software free of charge online, including source code and all the information needed to allow easy adaptability to specific user needs. The research examines the benefits of transforming proprietary, public domain and free modelling codes and software for better river management and development. In order to achieve this goal, a conceptual framework called Hydrological Software Forum (HSF) is developed. The role of the HSF to ensure effective sharing and knowledge transfer among students and researchers has also been identified. It is hope that the adoption of HSF can help bring a new revolution to the development and use of modelling codes and software for river applications.
\end{abstract}

Keywords: Hydrological software forum; Technology transfer; Knowledge sharing; Rivers

\section{Introduction}

Rivers and streams are the engine of growth and survival for ecosystems, different industries and our everyday life. The field of hydrology has evolved around the study of rivers and streams for the production of food, provision of shelter and building structures to withstand disasters such as floods, storms. Hydrology has emerged as a fast growing scientific field as a result of the rapid computer age. The development of computer models to represent river and stream's phenomena has received considerable interest among researchers. Computer models are generally repackaged as software to provide a user-friendly environment for river based moved from solely proprietary codes/software to a mix of proprietaries, or/and Free and Open Source Software (FOSS). FOSS is one of the cheapest and most effective solutions for technology transfer in software programs particularly in river applications. FOSS offers software free of charge online, including source code and all the information needed to allow easy adaptability to specific user needs. Thus, FOSS has a vital potential for knowledge transfer in poor countries e.g. developing countries [1-3] and also informative and practical knowledge transfer among students and researchers in hydrology and hydroinfomatics.

Regardless the enormous effect of development excellent software for specific river applications by hydrologists and other kinds of scientists, challenges of promoting knowledge sharing are still limited. This limitation has been focussed that commercially available software are of high costs and limits the use by individual universities and research institutions for further review for adaptability to specific needs [4]. The availability of FOSS however avoids these restrictions and opens up the industry to all possible contributors across the world. The overwhelming acceptance of FOSS demonstrates the significance of unconventional repackaging of property rights [5] and presents a bright future for transforming more proprietary software for river applications into FOSS. It must be emphasised that the growing acceptance of FOSS does not necessarily mean low price and low quality, FOSS products have been demonstrated to be of high quality compared to proprietary software [6,7]. One advantage FOSS has over proprietary software is that there is regular and continuous model development review. The moving of river based software and applications into FOSS framework will in the long-time terms provide a better forum for review, development and wider usage coverage.

As noted, FOSS concept has become the new most advance form of learning found on the web today. FOSS communities collaborate to provide and distribute quality software in the most sustainable manner. This concept somehow contradicts our formal education system present in schools where individual learning process is practiced from beginning to end. FOSS communities offer a better learning framework for learning to enhance the traditional learning system. This method is based on the learners, their environment and their preferences and focus more on the theory of social learning, collaboration, communication and sharing $[8,9]$. As the educational system is moving more into the digital age, FOSS based educational structure has a great potential in offering cross-boundary learning among students and researchers across the world [10]. The adoption of FOSS for river based modelling and related applications promotes cross-boundary learning, collaboration and sharing of experiences among students and researchers and gives developers the chance to getting more community support as compared to proprietary hydrological software.

River based software and modelling codes are varied from proprietary, public and free domain. Proprietary stands for purely commercial software, public domain means that parts/whole of the software is made available to users, private domain on the other hand means software codes are the user rights of the developers only and free means software is "free" for use under the specified terms and conditions by the developers. Suffice it to say; as it stands there is no recognised framework or generic procedure for bringing together all

*Corresponding author: Amos Kabo-bah, State Key Laboratories, Departmen of Hydrology and Water Resources, Hohai University, Nanjing, China, Tel: +86 13404140314; E-mail: kabobah@hhu.edu.cn, kabo-bah@greenwaterhut.org

Received April 02, 2012; Accepted July 10, 2012; Published July 13, 2012

Citation: Kabo-bah A, Yuebo X, Odoi J (2012) The Future of Free and Open Source Software (FOSS) for Hydrology and Water Resources Management Hydrol Current Res 3:136. doi:10.4172/2157-7587.1000136

Copyright: (c) 2012 Kabo-bah A, et al. This is an open-access article distributed under the terms of the Creative Commons Attribution License, which permits unrestricted use, distribution, and reproduction in any medium, provided the original author and source are credited. 
these categories of river based software and modelling codes into the FOSS concept. Hydrology is a very specific field and differs very much in needs compared to the numerous other professions; this therefore means that a generic model framework to guide both developers and wider community is necessary. Therefore the paper developed a generic model framework for migrating river based software and modelling codes into FOSS system. The paper also identifies some case studies of some river based software and applications which follow the principles of FOSS. The findings were achieved through relevant literature update, use of social networks such as LinkedIn.com and informal interviews with water resource professionals and personal experience in this field. The research hopes to provide some more insight for researchers and software developers in river based software and applications who are already thinking of migrating their products to FOSS scheme and also those who have not thought about the enormous benefits of this to reconsider their decisions. It must be noted that in this paper, the words software and applications are used interchanging to mean "any computer model or code that supports the understanding, prediction or forecasting of a phenomena in a river".

\section{Brief Concept - FOSS}

A new paradigm in software industry was considered firstly in 1984 when Stallman proposed a revolutionary idea with the Free Software Foundation (FSF) and subsequently confirms this in the Open Source Definition. Stallman's 1984 "GNU Manifesto" lays out the logic of the project and, importantly defined the meaning of the word "free" in "free software." According to him, Free does not necessarily mean zero price. Free rather means freedom - libre, not gratis [11]. The adoption and use of FOSS has become an international buzzword. In order for a software to be considered FOSS, it must comply with the standards lay out according to the Open Source Initiative (OSI) and the Free Software Foundation (FSF). The underlying principles encoded by both OSI and FSF include $[1,12]$ :
a. Freely available source code
b. Free to use for any purpose
c. Free to modify and to customize
d. Free to redistribute
e. Free to create derivative work
f. Free to join the development and cooperation

FOSS concepts and products are usually characterised by their low cost, voluntary work and consistent testing mechanism performed by many participants - sometimes term a community of developers. Developers participate according to their specific needs, this helps to promote the production speed and quality. FOSS content is defined as any kind of operational, artwork or creative content having no legal restriction relative to the people's freedom to use, redistribute, improve and share content. An example is Wikipedia ( $h t t p: / / w w w$. wikipedia.org); a Web-based free-content encyclopaedia project which allows users to edit its contents that have been written collaboratively contributed by volunteers [1].

The fundamental principle is that there should be free access to computer programming codes allowing anyone to be able to use, modify and circulate such modifications without having to pay anything. The rationale behind this is simple - programmers are allowed to work freely on source code of a computer program, facilitate easy collaboration to resolve errors and enables adaptation to specific needs and adaptability to different hardware platforms. Eric Raymond's in his manifesto in "The Cathedral and the Bazaar", he states that: given enough eyeballs, all bugs are shallow $[2,13]$. The proclamation of FOSS to mean free speech and not free as beer, raises new economic challenges. What can FOSS be sustainable without requisite capital to support operations? How can a team of volunteers be motivated to work on complicated software without remuneration? And many researchers have equally asked the same questions about survival of FOSS in the near future. As pointed out by Bonaccorsi and Rossi [30], the economic view point of Open Source software can be considered as a process innovation: a new and revolutionary process of producing software based on unconstrained access to source code as opposed to the traditional closed and property-based approach of the commercial work. In attempt to clearly understand how FOSS works, figure 1 explains the dynamic phenomena.

FOSS can be sustainable if some financial support is provided to support the works of the hardware which is used in production and maintenance of the systems that run these software and servers. As indicated in figure 1, somehow interested users of the software contribute accordingly to their capability on a flexible mode (either using through pay pal or other forms of online payment); these financial resources are used by the administrative team to take care of administrative costs for the software. Contributions and regular communication among community users, other programmers and founders of the software through an online blog system keeps a live feedback towards the improvement of the software.

\section{FOSS and Case Studies in River Applications}

FOSS development opens a new production model that greatly taps the distributed intelligence of participants in Internet communities. The ability of FOSS in a distributed environment, gives it an opportunity for students and researchers to participate in frontier innovation. Specially, FOSS has significant benefits for hydro-informatics and the general hydrology profession [14]. This gives academic researchers in hydrology a great opportunity to have their software and modelling codes more rapidly peer reviewed by scientific and ordinary communities across the world. This can significantly contribute towards added value to hydrological research. In most cases, scientific research in general is closed source and standalone, thus making it unable to integrate with the systems of the general community use, modification and verification. The study of hydrology and hydraulics provides fundamental sources of information for hydro-informatics. Hydroinformatics is the development of new improved modelling codes and tools; usually repackaged in user friendly stand alone programs

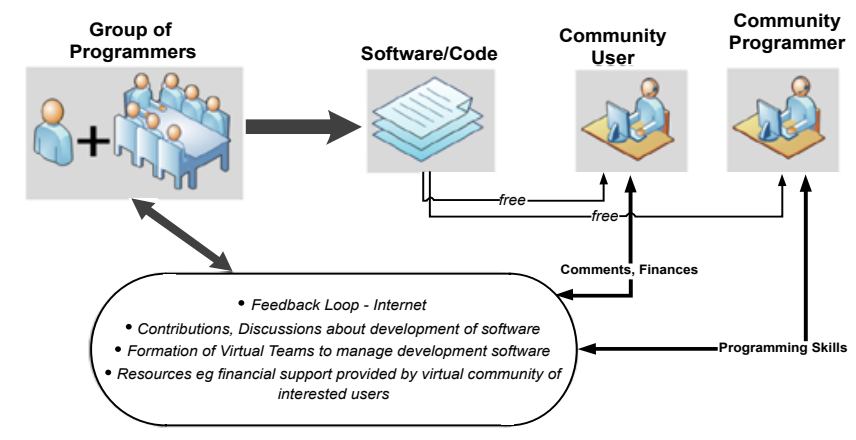

Figure 1: FOSS Sustainable Concept. 
- software. Therefore, the adoption of FOSS in hydrology, hydraulic and hydro-informatics will further enhance the close collaboration among these linked disciplines and further improve the understanding of river phenomena through better modelling practices. Some case studies about the growing acceptance of FOSS for river applications are further discussed below. Case studies here are meant to affirm the acceptance and the importance of repackaging products in river applications of FOSS. Therefore, they mere examples and do not reflect their exact relevance to river applications. Also, the discussion here is not intended to give a holistic overview of present today but to show the move for FOSS for river applications.

\section{Hydrological archive}

Wagener et al. [4] believed in the significance of free and exchange of software within the hydrological community and to this end, developed a framework for an open hydrological archive accessible through website. The aim of this website was to enable software exchange within the hydrological community and in effect minimize the time spent on programming. Software downloaded from the website was supposed to be free of charge. Unfortunately, this initiative was for short-time lived and currently not available. Therefore, this study fills in the gap to present a sustainable framework for the development of such similar networks for adopting FOSS for hydrology applications.

\section{Sourceforge.net \& freshmeat.net}

FOSS projects have opened a new direction for students, researchers and practitioners across the world. After all, FOSS is a public good [15]. For example, Deshpande and Riehle found that open source was expanding into new domains and applications at an exponential rate [16]. Some of these new areas for FOSS included hydrology, hydraulic and hydro-infomatics. Some of the websites that freely host FOSS applications are Sourgeforge.net and Freshmeat.net. Sourceforge.net is a popular directory that provides open source projects on a variety of applications including river applications. Freshmeat.net on the other hand offers open source projects basically for Unix based systems. These two websites receive over 2 million downloads per day. The success of these generic directories provides optimistic potentials for building a hydrological FOSS directory. An example of the some of the hydrological software or modelling codes can be downloaded from sourceforge.net (Table 1). The list presented in this table also describes the status of the modelling code or software. Since FOSS is under continuous development, fully operational software refer to those are completely developed, recommended by online users and also have dedicated community online support e.g. website or blog.

\section{Public domain \& free codes and applications}

The term public domain was not more pronounced until after the 18th Century when the British and French jurist used terms such as publici juris or propriété publique to refer to works that were not covered by copyright law [17]. Since this period, every subject area or profession has adopted a form of definition to best suit the practice within its environment. In this paper, public domain codes will be defined as modelling codes that are not covered by any law or property rights and in event allows modification or change of the original form of the code for specific river application needs. On the other hand free codes will refer to codes that can be obtained by the end user without

\begin{tabular}{|c|c|c|}
\hline Software & Application & Remarks \\
\hline Kalypso & $\begin{array}{l}\text { This is an application for geospatial modelling and simulation for hydrological and } \\
\text { hydraulic numerical models. }\end{array}$ & $\begin{array}{l}\text { Fully Operational } \\
\text { http://kalypso.bjoernsen.de/ }\end{array}$ \\
\hline PIHM Model & $\begin{array}{l}\text { This is a multi-process, multi-scale hydrologic model where the major hydrological } \\
\text { processes are fully coupled using the semi-discrete finite volume method. }\end{array}$ & $\begin{array}{l}\text { Fully Operational } \\
\text { http://www.pihm.psu.edu/ }\end{array}$ \\
\hline CUAHSI openHIS & This is an infrastructure for the advancement of hydrologic science and education & Fully Operational \\
\hline Heart & $\begin{array}{l}\text { This is a raster-based GIS-like application for the analysis of hydrological parameters } \\
\text { and the generation of associated reports }\end{array}$ & Fully Operational http://heart.sourceforge.net/ \\
\hline $\begin{array}{l}\text { Non-Point Source } \\
\text { Model Development } \\
\text { Tool }\end{array}$ & $\begin{array}{l}\text { This is web-based dynamic system modelling tool for online non-point pollution, } \\
\text { hydrology, and water supply planning. It also supports HSPF, CEQUAL and GWLF. }\end{array}$ & Fully Operational \\
\hline HidroSIG & $\begin{array}{l}\text { This is a GIS that supports raster and vector maps with modules oriented to the } \\
\text { hydrological analysis, time series, remote sensing and more. }\end{array}$ & $\begin{array}{l}\text { Fully Operational } \\
\text { http://poseidon.medellin.unal.edu.co/ hidrosig/index. } \\
\text { php?lang=en }\end{array}$ \\
\hline OpenFLUID & This is a software platform for modelling and simulation of mass fluxes in landscapes. & $\begin{array}{l}\text { Fully Operational } \\
\text { www.umr-lisah.fr/openfluid }\end{array}$ \\
\hline LARSIM & $\begin{array}{l}\text { This is a hydrologic model for modelling continuous runoff processes in catchments } \\
\text { and river networks. }\end{array}$ & $\begin{array}{l}\text { Fully Operational } \\
\text { http://www.kliwa.de/index.php?pos=wieweg/modelle/ } \\
\text { larsim/\&lang=en }\end{array}$ \\
\hline QuickHydro & $\begin{array}{l}\text { This is a hydraulic package that will calculate stormwater or wastewater flows in a } \\
\text { drainage network. }\end{array}$ & Operational \& under continuous development \\
\hline PIHMgis & $\begin{array}{l}\text { This is a platform independent and extensible linked to the Penn State Integrated } \\
\text { Hydrological Model (PIHMgis) }\end{array}$ & $\begin{array}{l}\text { Fully Operational, } \\
\text { http://www.pihm.psu.edu/pihmgis_home.html }\end{array}$ \\
\hline dotagwa & $\begin{array}{l}\text { This is web based for automation of delineation, discretisation, and calibration of a } \\
\text { hydrologic model. }\end{array}$ & Fully operational \\
\hline Citydrain & This is a toolbox for integrated modelling of urban drainage systems. & $\begin{array}{l}\text { Fully Operational } \\
\text { http://www.hydro-it.com/extern/IUT/citydrain/ }\end{array}$ \\
\hline Exclaim-2.0 & $\begin{array}{l}\text { This is especially meant for novice to access to hydrological, socio-economic and } \\
\text { environmental models and to allow easy assessment of the effects of landuse change } \\
\text { and climatic variation. }\end{array}$ & $\begin{array}{l}\text { Fully Operational } \\
\text { http://www.needs.ncl.ac.uk/exclaim/ }\end{array}$ \\
\hline SNL-EFDC & $\begin{array}{l}\text { This is a modified version of the EPA's public domain surface water flow, sediment } \\
\text { transport, and water quality model. }\end{array}$ & $\begin{array}{l}\text { Fully Operational } \\
\text { https://www.ohloh.net/p/SNL-EFDC }\end{array}$ \\
\hline
\end{tabular}

Source: sourceforge.net (June 10, 2011) 
any fees but might not be public domain. Therefore, it is possible to have codes that are free and in public domain but not necessarily meaning that they are free to end users.

Related studies in hydrological modelling e.g. in $[18,19]$ suggest that there few hydrological models and software that are in public domain e.g. Distributed Routing Rainfall-Runoff (DR3M-QUAL) model [20], Hydrological Simulation Program Fortran (HSPF) model [21-23], Stormwater Modelling and Management Model (SWMM) [24], QUAL2E-NCAS [25], One-dimensional Transport with Inflow and Storage (OTIS) model [26,27], Full Equations (FEQ) model [28], Estuarine, Coastal and Ocean Model Sediment transport (ECOMSED) model [29]. It must be mentioned that this list is only to emphasise the presence of public domain and free river applications but is not based on any preference or ranking; or is the intention to iterate all the free and public domain river applications in this paper.

This means that these models and software follow the similar principles of FOSS, allowing users to modify and redistribute code. However, this case is rather haphazard since there is no form of coordination of the activities regarding multiple users modifying public domain codes for their specific needs. There are no regular systems to share and learn together, as each user individually download codes or software and use it their risks with little or no input from original developers. Also, in this manner, it is difficult to control the overall quality towards the use and development in such applications. It is worth mentioning that, most of the advanced river applications and software are commercial. This limits research and educational institutions to introduce such application to their students; since students at the end of graduation do not obtain extended licensing terms. Hence, associated technical and practical problems associated with commercial software takes a considerable time to solve because only a few software developers and group of consultants have accessed to source code. Therefore, the FOSS community concept presented in this paper still presents a better case for hydrological software and applications as presented above.

\section{Hydrological Software Forum}

As discussed in previous section, the availability of few river applications as modelling codes and software via sourceforge.net cannot sustainably provide the hydrologist or river basin manager the opportunity to track which software or modelling codes are available. In addition, the development of these separate components does not meet the needed attention it deserves since in the already mentioned platforms are meant for different technical professions. Regardless of this, there are also some questions to be answered if complete transformation of all river applications into FOSS will be acceptable by the hydrological community. The questions are:

1. Will commercial software companies be willing to consider repackaging parts/whole of their products as basic versions to be used as FOSS?

2. Does the benefit of moving to FOSS truly give the needed motivation and reward for developers?

3. Can copyrighted software be easily transformed into free and open source?

The above three questions remains as long as the economic drivers and benefits for commercial developers of river applications are still difficult to predict in the next decades. This notwithstanding, there are examples like the FSI initiative, Geographic Resources Analysis
Support System (GRASS) or Linux that have economically gained from adopting FOSS. There exists also several literatures which suggests the economic benefits for companies going into FOSS technology. In some research, it is found out that companies that adopt FOSS promises to have a better sustainable future compared those who do not [30]. This is however subject to debate but the bottom line is that not all software can be completely FOSS but for the purposes of research and rapid improvement of river applications, the consideration of FOSS becomes very important.

Therefore, though, it is not possible to adopt completely FOSS by commercial hydrological software companies, it is possible that such companies can think of repackaging some aspects of the code as open source to allow for students, researchers and other innovative minds to facilitate the development processes of such software (see figure 2). Public domain based applications need to be guided by the FSI guidelines for FOSS into the acceptable standard form. However, free based applications will need to be transformed completely to open source such that they can comply with the FOSS principles. Once this is done, an organised directory and management system dubbed in this paper as Hydrological Software Forum (HSF) must be established. The HSF can be a research institution or organisation that that manages day to day operations of online submissions of river applications. Since this will be headed and led by an organisation, this means that dedicated volunteers towards the control and management of such a system have to be considered. The forum should allow also social feedbacks e.g. blog, Facebook or twitter. This aspect is particularly important for ensuring that developers and users can communicate their thoughts about the improvement of an application easily and faster. The forum apart from the management of this online database system must be responsible for scrutinising applications that are submitted and to control the general quality of submissions and feedbacks. In all cases, submissions must be guided by two basic criteria; all applications must contribute towards effective river management and development, and secondly they must be free and open source codes or software.

It is envisaged through such an innovative HSF system students and researchers globally can have access to hydrological software, get the chance to review, modify and adapt them to their different climate conditions. In this way, accelerated learning and experimentation can better improve the functionality of the particular hydrological software.

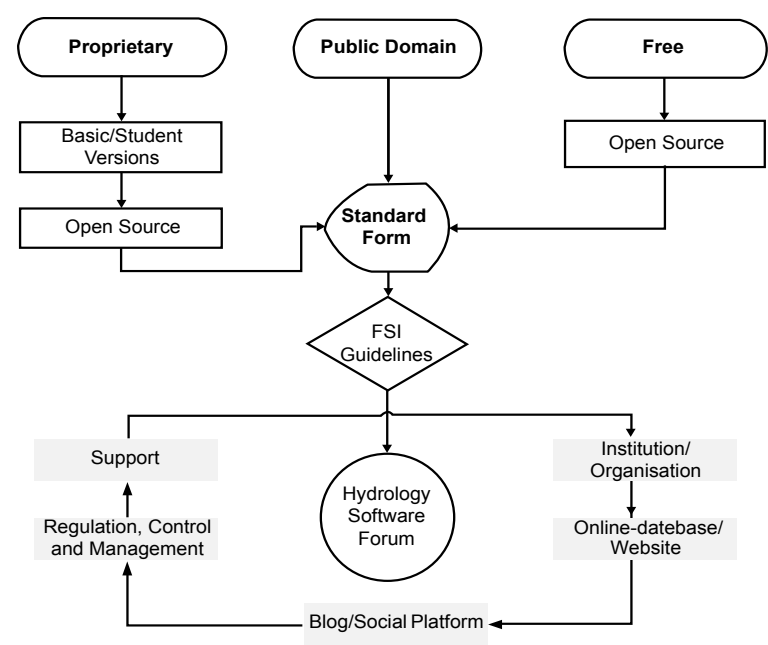

Figure 2: Adoption of Hydrology Software Forum Concept in hydrological community. 
Since there is a constant feedback mode through the FOSS community; developers of the hydrological software can get the chance to quickly address some bugs and solve some technical problems not properly addressed by the developers. In this manner, scientific peer review will be dynamic, rapid and have societal relevance than compared to the usual scientific review by some few academics. In other ways, other community users such as meteorologist, climatologist, atmospheric scientist, geologist and other professions will also have the benefit of adapting parts of the software to their specific needs. In this way integrated software will have the capacity to provide answers to a wide range of hydrological applications and other related scientific professions. As emphasised by Harvey and Han [14] hydrological research and FOSS can easily be integrated into the scientific method as one of the steps towards the academic peer review. This will facilitate and enhance the dissemination of academic results, easily build strong and new networks without having to reinvent the wheel and easily enable research results to be adopted by consultants and agencies.

It is also possible that in the long term with the implementation of the HSF system, river applications' computation time, calibration routines and validation processes could be enhanced. This could help us to better understand the fast changing dynamics in river processes such as floods and stormy events. FOSS is a new revolution in the software industry, and developers of hydrological models and software must accept the diversity [31] and consider it as a laudable opportunity to contribute their efforts towards facilitating research, promoting shared-knowledge on hydrological studies and increasing the reliability of hydrological software. As identified by Abdool [32], research and academic institutions have realised the advantages of FOSS and beginning to adopt FOSS products as a better alternative to proprietary products. A recent poll on Linkedin.com by survey on researchers willingness to adopt and use FOSS in the future by the authors, revealed that $73 \%$ of respondents are positive while $22 \%$ are not very certain of whether choosing between FOSS and proprietary software. In relative terms, informal discussions with researchers and students also suggest similar trends. Bitzer and Schröder [33] in their research on open source software found that the adoption of FOSS can better eliminate the current technology transfer problems associated with proprietary software. In a whole, the adoption of HSF for river applications can bring a new revolution to river based modelling in the next decades.

\section{Conclusion}

There is a new revolution in the software industry with the advent of the FOSS in recent times. The main advantage of FOSS over proprietary software is as a result of the freedom to modify, distribute and share the software codes with any legal restrictions. The research has shown that, the adoption of FOSS by research and academic institutions can greatly promote accelerated learning and experimentation for developing better hydrological applications and software. Though, there are few hydrological applications available at sourceforge.net; other hydrological models and software have been dubbed as Public Domain and free codes. However, the public domain and free hydrological software usually do not create a common-pool network for other developers and end users the chance to share their experiences together.

Therefore to accrue the benefits of FOSS for river applications, the research proposes a HSF structure that can be used as a guide to adopting FOSS for hydrology. Through such a forum, proprietary, public domain and free applications can be easily transformed to meet the needs of FOSS and gradually moved into the HSF. The HSF is proposed to be responsible for controlling and managing the activities of the online database and feedbacks submitted by both developers and community users. Also, HSF will be responsible for screening all applications submitted to the online portal to ensure that they meet the quality standards setup by the HSF. It is believed that the adoption of this system can support the efforts of community users such as meteorologist, climatologist, atmospheric scientist, geologist and other professions to share and transfer knowledge in understanding river phenomena better and faster.

\section{References}

1. Alkhatib J, Anis M, Noori H (2008) Open Source: The next big thing in technology transfer to developing nations. IAMOT 2008 Proceedings 1-11.

2. Camara G, Fonseca $F(2007)$ Information policies and open source software in developing countries. Journal of the American Society for Information Science and Technology 58: 121-132.

3. Cooksey R (2005) I Walk the Open Road: Toward an Open Source Philosophy Masters Thesis, The European Graduate School.

4. Wagener T, Gupta HV, Carpenter K, James B, Vazquez R, et al. (2004) A hydroarchive for the free exchange of hydrological software Website. Hydrological Processes 18: 389-391.

5. Weber S (2005) The success of open source. Harvard University Press.

6. Khalak A (2000) Economic model for impact of open source software. 1-16.

7. Michlmayr M, Hunt F, Probert D (2005) Quality practices and problems in free software projects. CiteULike 24-28.

8. Meizsner A, Healy A, West D, Conolly T, Glott R, et al. (2008) FLOSS-like education transfer report.

9. Wenger E (1998) Communities of practice and Social Learning system Organization Articles 7: 225-246.

10. Lin YW, Zini E (2008) Free/libre open source software implementation in schools: Evidence from the field and implications for the future. Computers \& Education 50: 1092-1102.

11. Stallman RM (1985) The GNU manifesto. 1-12.

12. Chege M (2008) Ubuntuism, commodification, and the software dialectic Social Science Electronic Publishing.

13. Raymond ES (2001) The cathedral and the bazaar: musings on Linux and open source by an accidental revolutionary. O'Reilly Linux.

14. Harvey H, Han D (2002) The relevance of Open Source to hydroinformatics. $J$ Hydraul Eng 4: 219-234.

15. Von Krogh G, von Hippel E (2006) The promise of research on open source software. Management Science 52: 975-983.

16. Deshpande A, Riehle D (2008) The total growth of open source. Open Source Development, Communities and Quality 275: 197-209

17. Ginsburg J (2007) 'Une chose publique'? The Author's Domain and the Public Domain in Early British, French and US Copyright Law. Copyright Law: A Handbook of Contemporary Research 133-160.

18. Papanicolaou AN, Elhakeem M, Krallis G, Prakash S, Edinger J (2008) Sediment Transport Modeling Review---Current and Future Developments. Journal of Hydraulic Engineering 134: 1-14.

19. Zoppou C (2001) Review of urban storm water models. Environmental Modelling \& Software 16: 195-231.

20. Alley WM, Smith PE, Survey G (1982) Distributed Routing Rainfall-Runoff Model: Version II. US Geological Survey.

21. Bicknell BR, Imhoff JC, Kittle JL, Donigian AS, Johansan RC (1997) Hydrological simulation program--Fortran: User's manual for version 11. US Environmental Protection Agency.

22. Donigian AS, Bicknell BR, Imhoff JC, Singh VP (1995) Hydrological Simulation Program-Fortran (HSPF). Computer models of watershed hydrology. 395-442. 
Citation: Kabo-bah A, Yuebo X, Odoi J (2012) The Future of Free and Open Source Software (FOSS) for Hydrology and Water Resources Management. Hydrol Current Res 3:136. doi:10.4172/2157-7587.1000136

Page 6 of 6

23. Johanson RC, Imhoff JC, Kittle JL, Donigan A (1984) Hydrological Simulation Program--FORTRAN(HSPF): Users Manual for Release 8.0.

24. Huber W, Dickinson R (1988) Storm-Water Management Model, Version 4. Part a: user's manual.

25. Brown LC, Barnwell TO (1987) The enhanced stream water quality models QUAL2E and QUAL2E-UNCAS: documentation and user manual.

26. Bencala KE, Walters RA (1983) Stimulation of solute transport in a mountain pool-and-riffle stream: A transient storage model Water resources Research. 19: $718-724$

27. Runkel R (1998) One-dimensional transport with inflow and storage (OTIS): A solute transport model for streams and rivers. US Geological Survey WaterResources Investigation Report 98: 4018.

28. Franz DD, Melching CS, County DP (1997) Full Equations (FEQ) model for the solution of the full, dynamic equations of motion for one-dimensional unsteady flow in open channels and through control structures.

29. Blumberg A (2002) A primer for ECOMSED. Mahwah NJ: Hydro Qual Inc 1-194.

30. Bonaccorsi A, Rossi C (2003) Why Open Source software can succeed. Research Policy 32: 1243-1258.

31. Hawthorne M, Perry D (2006) Software engineering education in the era of outsourcing, distributed development, and open source software: challenges and opportunities. Software Engineering Education in the Modern Age 166-185.

32. Abdool S (2005) The theory of FOSS and its acceptance in developing nations

33. Bitzer J, Schröder PJH (2006) The economics of open source software development: An introduction. The economics of open source software development 1-13 